\title{
Duration of Gastric Digestion in Fishes
}

\author{
V. B. Tseitlin \\ Shirshov Institute of Oceanology, Academy of Sciences, 117218 Moscow, USSR
}

ABSTRACT: For calculating the duration of gastric digestion in fishes the following empirical equation is suggested:

$$
T=T_{0} W^{s} Y_{m}^{0.62} \tau
$$

where $T=$ digestive duration (h); $T_{o}$ and $s=$ constant characteristics for different ecological groups; $W=$ fish weight $(\mathrm{g}) ; y=$ $M_{p} / W_{i} M_{p}=$ initial weight of food portion $i=\operatorname{temperature~function~}(\tau=\exp [0.0806(20-t)]) ; t=$ temperature $\left({ }^{\circ} \mathrm{C}\right)$. Fishes are divided into three groups: cold-water, temperate-water and warm-water species (the difference of average ambient temperatures for cold-water and warm-water species is assumed to be $\sim 10-12^{\circ} \mathrm{C}$ ). The value of $T_{\mathrm{o}}$ for these groups is equal to $84.1,69.8$ and 57.9 , respectively; $s=0.342,0.262$ and 0.182 . At habitat temperatures $\left(\sim 10^{\circ} \mathrm{C}\right)$ characteristic of cold-water fishes, digestive duration is about equal to that for warm-water species at $20^{\circ} \mathrm{C}$. The correlation of parameters characterizing feeding and digestion of fishes with metabolic characteristics is briefly considered.

\section{INTRODUCTION}

Data on daily rations for fishes are required for many purposes - e. g. for establishing dietary schedules in artificial breeding, or for elucidating the role of the fishes in the trophic network. The latter implies studies on fishes feeding under natural conditions. However, for calculating a daily ration (for example, on the basis of the amount of food in the stomach of individuals caught at different times), it is necessary to know the duration of digestion. The duration of digestion is always determined under laboratory conditions. However, such studies are not possible in many fish species, e. g. in oceanic deep-sea fishes. Data on daily rations of such fishes must be obtained indirectly. It is this problem - feeding of mesopelagic and bathypelagic fishes - that has led to the work reported here. Important aspects of fish nutrition and digestion have been reviewed in 'Marine Ecology', especially by Pandian (1975), Kinne (1977) and Conover (1978).

Digestive processes differ in different fish species, but there are elements common to many fishes, and these could serve as a basis for estimating general parameters of digestion. A well-known and general relationship, is the dependence of oxygen consumption rate $(Q)$ on weight $(W)$ and temperature $(t)$ :

$$
Q=a W^{\alpha} / \tau(t)
$$

where $a$ and $\alpha=$ constants; $\tau(t)=$ temperature correc- tion. Equation (1) may be employed over a wide taxonomic range as a rough estimate of energy consumption, i. e. the values $a, \alpha$ and the function $\tau(t)$ are similar for many species.

In this paper, an attempt is made to establish a similar relationship for the duration of gastric digestion, i.e. the time in which the food taken up is completely evacuated from the stomach. This value is difficult to determine under experimental conditions. This is especially so when the phases of effective and residual digestion are pronounced (Karpevitch and Bokova, 1936). Since the main portion of the food is digested during the first phase, and the duration of the second phase varies greatly, we assume the time of gastric digestion to be the interval in which $90 \%$ of the original food portion is evacuated from the stomach.

\section{CALCULATING DIGESTION TIME}

The basic factors which determine the duration of digestion in fishes are: temperature, weight of food portion in the stomach, and fish weight (Kapoor et al., 1975). In addition, duration of digestion may substantially depend on food composition and quality. Therefore, data obtained with natural food are of particular interest for ecologists.

Some studies (Beamish, 1972; Jones, 1974; Jobling et al., 1977) suggest that the dependence of gastric diges- 
tive duration on the above-mentioned basic factors may be summarized as follows:

$$
T=\tau(t) Y\left(y_{m}\right) w(W)
$$

where $T=$ time of gastric digestion; $y_{m}=M_{p} / W_{1} M_{p}=$ initial food weight in the stomach; $W=$ fish's weight. Thus $T$ is determined by multiplication of the three functions, each depending upon a single value - temperature, relative food weight and fish weight, respectively. This is an approximation; the paper by Jobling et al. (1977) suggests that temperature influence on digestion time depends upon the amount of food in the stomach. Using Equation (2) we admit that this effect is small. We will determine the form of each function involved in Equation (2).

Temperature dependence of digestion rate (rate of food evacuation from stomach, $\mathrm{g} \mathrm{h}^{-1}$ ) was measured repeatedly over a wide range of temperatures. However, Kapoor et al. (1975) mention in their review that many tests were carried out after an insufficiently long period of acclimation resulting in excessively high temperature coefficients $\left(Q_{10}>3\right)$. If we turn to experimental results free from this shortcoming, the dependences $T(t)$ prove to be close to the temperature curves of Krogh and Arrhenius. Specifically, Jones (1974) suggests that the dependence of digestion rate on temperature should be determined from the equation:

$$
\tau(t)=10^{0.035\left(t_{0}-t\right)}=\exp \left[0.0806\left(t_{0}-t\right)\right]
$$

where $t=$ temperature during observations; $t_{0}=$ temperature at which the value of the pre-exponential multiplier was determined. Calculations according to Equation (3) coincide well with Arrhenius' curve. Some other data for $T(t)$ correspond somewhat better to Krogh's curve which diverges from (3) in the range of low temperatures. But, since the divergence from (3)

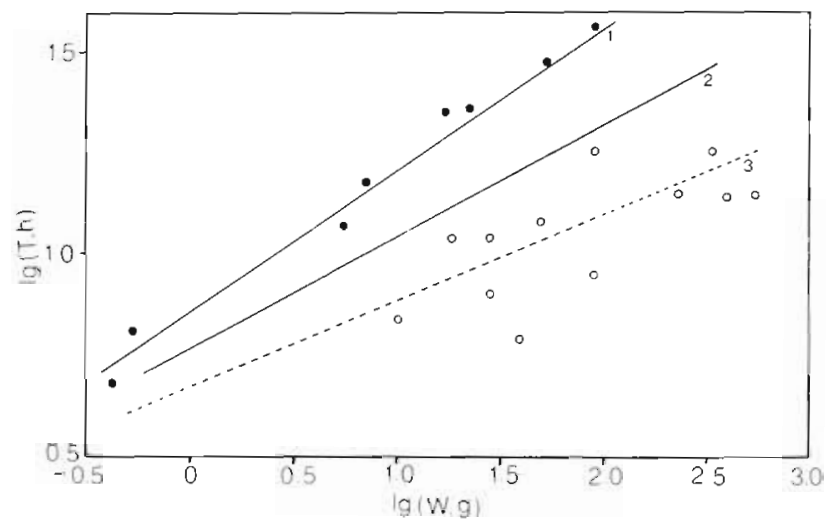

Fig. 1. Dependence of gastric digestion duration on fish weight. Filled circles: experimental data for warm-water fishes; open circles: same for cold-water species. All experimental data adjusted to $20^{\circ} \mathrm{C}$; relative value of food portion $y_{m}=0.02$. Lines 1,2 and 3 correspond to regression equations for warm-water, temperate-water and cold-water fishes, respectively is not in excess of $20 \%$ this equation will be used for calculating the dependence on temperature. The corresponding value of $Q_{10}$ is 2.24 .

Most researchers believe that an increase in the food portion raises both the evacuation rate of food from the stomach (in $\mathrm{g} \mathrm{h}^{-1}$ ) and the residence time for food in the stomach, i. e. digestion time. But the amount of food in the stomach depends on time non-linearly, and it is not always clear what rate of digestion is concerned, i. e. an overall rate or a rate relating to a certain phase of the process. Consequently, data regarding food-portion effects on the digestive rate cannot be used for assessing influences on digestive duration. Data regarding the dependence of digestive duration on the relative food-portion weight was presented by Beamish (1972) and Jobling et al. (1977). According to the former $T \sim y_{m}{ }^{0.5}$, according to the latter $T \sim y_{m}{ }^{0.74}$. Since no data exist to support a choice between these two equations we will use the mean value of the index, assuming

$$
Y\left(Y_{m}\right) \sim Y_{m}^{0.62}
$$

In order to determine the dependence of $w(W)$ from different experimental data, it is necessary to reduce them to a single relative portion weight and to one temperature. As a standard we chose $y_{m}=0.02$ and $t=$ $20{ }^{\circ} \mathrm{C}$; then $T=$ const. $W(W)$. Having divided the experimental $T$ values by $y_{m}{ }^{0.62}$ values, on the basis of which they have been derived, and having multiplied by $0.02^{0.62}$ and $\tau=\exp [0.0806(20-t)]$, we obtained the results presented in Figure 1. The experimental data used were taken from Hunt (1960), Pandian (1967), Brett and Higgs (1970), Elliott (1972), Gerald (1973), Swenson and Smith (1973), Jobling et al. (1977) and Gorelova (1979). There is need to divide the data into two groups - warm-water and cold-water fishes. Warm-water fishes dwell at temperatures ranging approximately from $15^{\circ}$ to $30^{\circ} \mathrm{C}$, cold-water fishes approximately from $2{ }^{\circ}$ to $20^{\circ} \mathrm{C}$. Thus, average habitat temperatures differ by $10^{\circ}$ to $12{ }^{\circ} \mathrm{C}$. Warm-water species are: Megalops cyprinoides, Chaenobryttus gulosus, Ophiocephalus punctatus, Lutianus peru; cold-water species are: Melanogrammus aeglefinus, Stezostedion vitrem, Limanda limanda, Merlangius merlangus, Oncorchyncus nerka, Gadus morhua, Salmo trutta. The regression equation for warm-water species is:

$$
T=7.44 W^{0.342 \pm 0.026}
$$

(correlation coefficient for logarithms $r=0.98$ ); for cold-water species:

$$
T=5.12 W^{0182 \pm 0.059},(r=0.70)
$$

Values of the exponent for $W$ for individual species are: 0.395 (Limanda limanda [Jobling et al., 1977]); 
0.200 (Melanogrammus aeglefinus [Jones, 1974]); 0.395 (Megalops cyprinoides [Pandian, 1967]). Jones (1974) and Jobling et al. (1977) derived such weight dependences at constant values of $y_{m}$ and temperatures. Experimental $y_{m}$ values ranged from 0.02 to 0.67 in warm-water species, and from 0.0015 to 0.054 in cold-water species. The temperatures ranged, respectively, from $20^{\circ}$ to $28^{\circ} \mathrm{C}$ and from $6{ }^{\circ}$ to $20^{\circ} \mathrm{C}$. The fact that the dependence $T(W)$ was not only preserved, but the correlation coefficients were sufficiently high, indicates that errors in Equations (3) and (4) were not excessive.

In order to obtain the duration of digestion at arbitrary $y_{m a}$ and $t$ values, the right-hand side of Equations (6) and (7) should be multiplied by $y_{m}{ }^{0.62}$ and $\tau=\exp$ $[0.0806(20-t)]$. The final result is then:

$$
\begin{aligned}
& \left.T_{\text {warm }}=84.1 W^{0.34} y_{m}{ }^{0.62} \exp [0.080620-t)\right] \\
& T_{\text {cold }}=57.9 W^{0.18} Y_{m}{ }^{0.62} \exp [0.0806(20-t)]
\end{aligned}
$$

If fishes dwell at temperatures from $10^{\circ}-12^{\circ} \mathrm{C}$ to $20^{\circ}-22^{\circ} \mathrm{C}$, it is difficult to categorize them into either of the above-mentioned groups. In this case it is reasonable to calculate $T$ from the equation for temperature-water species:

$$
T_{\text {temp }}=69.8 W^{0.26} y_{m}^{0.62} \exp [0.0806(20-t)] .
$$

The value $T_{\text {temp }}$ is the geometrical mean between $T_{\text {warm }}$ and $T_{\text {cold }}$. All three values yield the time in which $90 \%$ of the initial food portion is digested.

\section{DISCUSSION}

If the energy acquired by fishes, as daily ration $R$ is utilized exclusively for metabolic processes, it follows:

$$
U R=24 Q,
$$

where $U=$ food assimilability. The use of this equation suggests that we neglect energy consumption for growth and reproductive products, and consider fishes to live under approximately constant conditions, as is the case for tropical and deep-sea fishes.

The equation for $R$ can be presented as (Gorelova and Tseitlin, 1979):

$$
R=\frac{24 N_{f} Y_{m} W}{T N}
$$

where $N_{f} / N=$ a portion of fishes with food in their stomachs. Substituting Equations (1) and (2) for (11) and taking into consideration that, according to Equations (2)-(7), the general form of the equation for $T$ is:

we obtain

$$
T=T_{o} W^{s} y_{m}^{0.62} \tau \text {. }
$$

$$
\frac{U\left(N_{f} / N\right) y_{m}^{0.38} W^{1-s}}{T_{0} \tau}=\frac{a W^{\alpha}}{\tau}
$$

Assuming that the product $U\left(N_{t} / N\right) Y_{m}{ }^{0.38}$ does not depend on weight (or at least that this dependence is so weak that it may be neglected) it follows from (13):

$$
\alpha=1-S
$$

In Equations (6) and (7) $s$ values range from 0.12 to 0.37 , and hence the limits of $\alpha$ changes in (14) will be

$$
\alpha=0.63-0.88
$$

Approximately the same fluctuations of values (with the mean $\approx 0.75$ ) are observed in practice (Winberg, 1976): for cold-water species, as follows from Equations (14) and (9), $\alpha=0.82$, for warm-water species, $\alpha$ $=0.66$, and for temperate-water fishes, $\alpha=0.74$. Having divided zooplankters into three large groups boreal, tropical, and temperate - Ikeda (1970) found that $\alpha$ values for these groups are equal to $0.83,0.54$ and 0.69 , respectively. The tendency towards increase in $\alpha$ with a decline in ambient temperature is obvious in both cases.

One more conclusion that can be inferred from Equation (13): the necessity to choose the same temperature function $\tau$ for metabolism and digestion, provided that the ration depends on temperature only via $\tau$.

Finally, having determined in Equation (13) the dependence of both parts of the equation on weight, the expression for the 'metabolic level' - values a can be written:

$$
\mathrm{a}=\frac{U\left(N_{\mathrm{f}} / N\right) Y_{m}^{0.38}}{T_{\mathrm{o}}}, \mathrm{g} \mathrm{h}^{-1}
$$

Here the metabolic level is expressed only through values connected with food and digestion: food assimilability $(U)$ and size of average portion $g^{-1}$ fish weight $\left(y_{m}\right) \cdot N_{f} / N$ characterizes the relative time of stomach functioning. As far as $T_{0}$ is concerned, it is possibly connected with the activity of digestive enzymes of the given ecological group of fishes. Expressing $a$ in terms of parameters of the process, which is far simpler than in terms of general metabolism, Equation (15) establishes the biological meaning of $a$.

The results obtained reveal that under similar conditions (i. e. at equal food portions and temperature) digestion in cold-water species proceeds far more rapidly than in warm-water species. But taking into account the above-mentioned difference of average habitat temperatures, we find that at a natural temperature of $10{ }^{\circ} \mathrm{C}$ cold-water fishes require nearly the same time to digest a similar food portion as do warmwater fishes at $20^{\circ} \mathrm{C}$.

Table 1 offers information on the correlation of calculations based on the equations suggested, together with experimental data. The $T_{\exp }$ values shown were not used for deriving the equations. The calculations were performed by using Equation (9). As 
Table 1. Experimental ( $\left.T_{\text {exp }}\right)$ and calculated $\left(T_{\text {cal }}\right)$ values of digestive duration for Barents Sea gobies $\left(t=10^{\circ} \mathrm{C}\right)$

\begin{tabular}{|c|c|c|c|c|c|}
\hline $\begin{array}{c}W \\
(g)\end{array}$ & $y_{m}$ & $\begin{array}{c}\text { Share of initial } \\
\text { portion digested } \\
\text { during } T_{\text {exp }} \%\end{array}$ & $\begin{array}{l}T_{\exp } \\
\text { (h) }\end{array}$ & $\begin{array}{l}T_{c a l} \\
\text { (h) }\end{array}$ & $\frac{T_{c, a l}}{T_{\text {exp }}}$ \\
\hline 78 & 0.192 & 88.6 & 72 & 103 & 1.43 \\
\hline 129 & 0.109 & 90.5 & 96 & 79 & 0.83 \\
\hline 209 & 0.213 & 87.3 & 96 & 131 & 1.36 \\
\hline 339 & 0.086 & 87.7 & 96 & 82 & 0.85 \\
\hline 247 & 0.121 & 91.6 & 96 & 95 & 0.99 \\
\hline 64 & 0.178 & 93.0 & 120 & 100 & 0.83 \\
\hline
\end{tabular}

far as can be judged by the data available, the divergence $T_{\text {cal }}$ from $T_{\text {exp }}$ does not lie outside the limits of individual variability of digestive time values.

To compare observed data together with calculations by Equations (8)-(10) one need to know fish wet weight $W(\mathrm{~g})$, relative weight of initial food portion $y_{m}$ (dimensionless), temperature $t\left(\mathrm{C}^{\circ}\right)$ and $T(\mathrm{~h})$ - the interval of time in which $90 \%$ of the initial food portion is evacuated from the stomach. The latter is especially important if the amount of food in the stomach decreases exponentially. In such cases duration of digestion of $90 \%$ of the initial portion is half that for $99 \%$.

The equations derived for duration of gastric digestion are based on a comparatively small number of experimental studies and thus are in need for refinement. It is especially desirable to obtain data on digestive durations for cold-water fishes of small weight. Apart from this, further research into the dependence of $T$ on the value of $y_{m}$ is necessary.

\section{LITERATURE CITED}

Beamish, F. W. H. (1972). Ration size and digestion in large mouth bass, Micropterus salmoides Lacépède. J. Zool. 50 : $153-164$

Brett, I. R., Higgs, D. A. (1970). Effect of temperature on the rate of gastric digestion in fingerling sockeye salmon, Oncorhynchus nerka. J. Fish. Res. Bd Can. 27: 1767-1779

Conover, R. J. (1978). Transformation of organic matter. In: Kinne, O. (ed.) Marine ecology, Vol. IV, Dynamics. Wiley, Chichester, pp. 221-449

Elliott, J. M. (1972). Rates of gastric evacuation in brown trout, Salmo trutta $L$. Freshwat. biol. 2: 1-18

Gerald, V. M. (1973). Rate of digestion in Ophiocephalus punctatus. Comp. Biochem. Physiol. 46A: 195-205

Gorelova, T. A. (1979). On the experimental data of digesting time in juveniles Lutianus peru (Nichols et Murphy). Vopr. Ikhtiol, 19: 1136-1139

Gorelova, T. A., Tseitlin, V. B. (1979). Feeding of mesopelagic fishes, genus Cyclothone. Okeanologiya (Moscow). 19; $1110-1115$

Hunt, B. P. (1960). Digestion rate and food consumption of Florida gar, warmouth and largemouth bass. Trans. Am. Fish. Soc. 89: 206-211

Ikeda, T. (1970). Relationship between respiration rate and body size in marine plankton animals as a function of the temperature of habitat. Bull. Fac. Fish. Hokkaido Univ. 21: 91-112

Jobling, M., Gwyther, D., Grove, D. J. (1977). Some effects of temperature, meal size and body weight on gastric evacuation time in the dab Limanda limanda (L). J. Fish. Biol. 10: $291-298$

Jones, R. (1974). The rate of elimination of food from the stomachs of haddock, Melanogrammus aeglefinus, cod, Gadus morhua, and whiting, Merlangius merlangus. J. Cons, int. Explor. Mer 35: 225-243

Kapoor, B. G., Smith, H., Verighina, I. A. (1975). The alimentary canal and digestion in teleosts. Adv. mar. Biol. 13: 109-239

Karpevitch, A. F., Bokova, E. N. (1936). Rates of digestion in sea fishes. Zool. Zh. 15: 143-168

Kinne, O. (1977). Cultivation of animals: research cultivation. In: Kinne, O. (ed.) Marine ecology, Vol. III, Cultivation, Part 2. Wiley, Chichester, pp. 597-1293

Pandian, T. J. (1967). Intake, digestion absorption and conversion of food in the fishes Megalops cyprinoides and Ophiocephalus striatus. Mar. Biol. 1: 16-32

Pandian, T. J. (1975). Mechanisms of heterotrophy. In: Kinne, O. (ed.) Marine ecology, Vol. II, Physiological mechanisms, Part 1. Wiley, London, pp. 61-249

Swenson, W. A., Smith, L. L. (1973). Gastric digestion, food consumption, feeding periodicity and food conversion efficiency in walleye, Stizostedion vitreum vitreum. J. Fish. Res. Bd Can. 30: 1327-1336

Winberg, G. G. (1976). Dependence of energy metabolism on the body mass in aquatic poikiloterms. Zh. Obshch. Biol. 37: $56-70$ 